\title{
Influence of Antiretroviral Therapy on the Metabolic Profile of People Living with HIV Followed at University Hospital, Cotonou,
} Benin

\author{
Djimon Marcel Zannou ${ }^{1,2 *}$, Angèle Azon-Kouanou1,2, Manoela Christelle Ahomadegbe1,2, \\ Kuessi Anthelme Agbodande1, Jocelyn Akakpo², Comlan Albert Dovonou ${ }^{3}$, \\ Kuassi Daniel Amoussou-Guenou${ }^{4}$, Yessoufou Tchabi ${ }^{5}$, Gabriel Ade ${ }^{1}$, Fabien Houngbe ${ }^{1}$ \\ ${ }^{1}$ Internal Medicine Department, National University Hospital (CNHU-Hubert K. Maga), Cotonou, Benin \\ ${ }^{2}$ Ambulatory Care Center for People Living with HIV at CNHU-Hubert K. Maga, Cotonou, Benin \\ ${ }^{3}$ Internal Medicine Department, Prefectural University Hospital of Borgou, Parakou, Benin \\ ${ }^{4}$ Endocrinology and Metabolic Diseases Department at CNHU-Hubert K. Maga, Cotonou, Benin \\ ${ }^{5}$ Cardiology Department, CNHU-Hubert K. Maga, Cotonou, Benin \\ Email: ‘djmzannou@yahoo.fr, angele.azonkouanou@gmail.com, ladymanoela@yahoo.fr, \\ agbotem@yahoo.fr, jocen12@yahoo.fr, dovcom1@yahoo.fr, danielamousguen@yahoo.fr, \\ y.tchabi@gmail.com, gabriade@yahoo.fr, fab2012jos@yahoo.com
}

Received 21 October 2015; accepted 29 November 2015; published 2 December 2015

Copyright (C) 2015 by authors and Scientific Research Publishing Inc.

This work is licensed under the Creative Commons Attribution International License (CC BY). http://creativecommons.org/licenses/by/4.0/

C. (†) Open Access

\section{Abstract}

Introduction: Since the advent of antiretroviral therapy, the vital prognosis of people living with HIV (PLWHA) has improved significantly. However, the risk of metabolic complications is high, thus making the bed of cardiovascular disease. Our objective was to compare the prevalence of metabolic abnormalities among PLWHA receiving ARVs to that observed in those who are not treated. Methods: We conducted a cross-sectional study (January to April 2010) at the PLWHA ambulatory care center of national university hospital (CNHU-Hubert K. Maga) in Cotonou, Bénin. We recruited 420 PLWHA (210 treated for at least 6 months and 210 untreated). We determined the prevalence of metabolic syndrome (MS) defined by the criteria of NCEP-ATP III, and the prevalence of abnormal glucose and lipid, and lipodystrophy. Association between metabolic syndrome and ARVs used was analyzed by binomial regression. Confidence intervals were calculated at $95 \%$ and $5 \%$ alpha level. Results: The prevalence of MS was $16 \%(18 \%$ of patients treated vs. $13 \%$ of non-treated, $p=0.18)$. That of hyperglycemia was $18 \%(30 \%$ of patients treated vs. $6 \%$ of untreated; $p<0.001)$ and of diabetes $7 \%(12 \%$ of patients treated vs $2 \%$ of untreated; $p<0.0001)$.

\footnotetext{
"Corresponding author.
}

How to cite this paper: Zannou, D.M., et al. (2015) Influence of Antiretroviral Therapy on the Metabolic Profile of People Living with HIV Followed at University Hospital, Cotonou, Benin. Open Journal of Internal Medicine, 5, 106-114.

http://dx.doi.org/10.4236/ojim.2015.54015 
The total cholesterol prevalence was $29 \%$ ( $44 \%$ of treated vs $13 \%$ of untreated; $p<0.02$ ). That of lipodystrophy in 210 patients was $29 \%$ (lipoatrophy $16 \%$, lipohypertrophy 8\%, mixed form 6\%). Factors associated with metabolic syndrome were age, hypertension, diabetes (personal or family), $B M I$, exposure to stavudine $(O R=1.59[1.02$ to 2.47$], p=0.04)$ and indinavir booted with ritonavir (OR $=2.23$ [1.11 to 446$], p=0.02)$. Conclusion: The metabolic abnormalities are more common in PLWHA treated with ARVs. Preventing these anomalies should be made to the initiation of antiretroviral therapy and during the therapeutic monitoring.

Keywords

Metabolic Syndrome, Diabetes, Dyslipidemia, Antiretroviral Therapy, HIV Infection

\section{Introduction}

Since the advent of antiretroviral therapy (ART), the vital prognosis of people living with HIV (PLWHA) have improved significantly. However, the risk of metabolic complications including metabolic syndrome is high [1]. These complications make the bed of cardiovascular disease in PLWHA regardless of the virus's own complications [2]. The incidence of cardiovascular disease will be explosive in PLWHA treated with ART. The study "Data collection on adverse events of anti-HIV Drugs (DAD)" provides, for example, a 26\% increase in the incidence of myocardial infarction per year during the first 4 to 6 years of exposure to ARVs [3]. In addition, cardiovascular diseases are cited in France since 2000 as the third leading cause of death among PLWHA treated with ART and who have immuno-virologic success [4]. In one of our previous studies [5], metabolic syndrome according to definition of the IDF (International Diabetes Federation) appeared in 13\% of patients after a median of 15 months of antiretroviral therapy. Diabetes (8\%) and hypercholesterolemia (35\%) were also observed. We had worked on a small sample of 88 patients treated. To appreciate the real impact of antiretroviral therapy on metabolic syndrome we choose to compare PLWHA treated by ARVs to those who are untreated. Our goals were to:

1) Determine the prevalence of metabolic syndrome and other metabolic abnormalities in PLWHA treated by ART and in those who are untreated.

2) Identify factors associated to metabolic syndrome in these patients.

\section{Patients and Methods}

\subsection{Type of Study}

The work was performed at the PLWHA ambulatory care center (CTA) of national university hospital (CNHUHubert K. Maga) in Cotonou, Bénin. This is a cross-sectional study, descriptive and analytical, conducted from January to April 2010 within the CTA active cohorte.

\subsection{Study Population}

Sampling: The study involved two groups of patients living with HIV: those treated with ART and those who had just been admitted to the center or that were followed but had not yet started treatment. The sample size was determined by comparison of two proportions formula and was 356 subjects. For convenience, we had successively recruited during consultations 420 patients: 210 treated with ART and 210 untreated.

Inclusion criteria: Selected patients should be 18 years or older, be regularly followed in the center; have given their informed consent to participate in the study. Those treated should have started ART for at least 6 months. Patients with a Karnofsky index $<70 \%$ or suffering from any ailment requiring hospitalization and pregnant women were not included.

\subsection{Variables Studied}

Demographic variables, anthropometric and lifestyles: The age, gender, tobacco and alcohol consumption were recorded by a questionnaire and patient's clinical file. Height was measured with a wall-mounted microtoise to 
the nearest $0.5 \mathrm{~cm}$. Weight was measured with a weighing scale in adults marque "SECA". Body mass index (BMI) was calculated by dividing weight $(\mathrm{kg})$ by the square of height $\left(\mathrm{m}^{2}\right)$. The BMI was classified in accordance with the WHO classification. Waist circumference was measured midway between the inferior angle of the ribs and the suprailiac crest with a measuring tape to the nearest $1 \mathrm{~cm}$.

Clinical, biological and therapeutic variables: Personal and family history of hypertension and diabetes were searched by questionnaire. The type of HIV, WHO clinical stage, CD4 count and, ART regimen and duration were obtained by patient's clinical records. We measured Blood pressure with a mercury sphygmomanometer mark "VAQUEZ", in the sitting position on the upper arm after-15-min rest period. A venous sample was performed in patients at baseline, before breakfast, to dose fasting glucose, triglycerides, total cholesterol, LDL cholesterol and HDL cholesterol. These samples were aliquoted and then stored in the laboratory of CTA. Laboratory tests were carried out by the enzymatic method end point in the hospital laboratory biochemistry after subjects recruitment phase. The dependent variable was the presence of metabolic syndrome. It was determined in the 2 groups.

Operational definitions: Smoking was retained if the subject claims to have an estimated smoking at least 10 pack-years and alcoholism if the daily consumption of alcoholic beverage is more than one liter in women and one and a half liters in humans. Metabolic abnormalities have been determined as follows:

- Metabolic syndrome was defined according to the criteria of NCEP-ATP III (National Cholesterol Education Program-Adult Treatment Panel III), namely, the existence of at least 3 of 5 following criteria: waist circumference $>102 \mathrm{~cm}$ in women and $>88 \mathrm{~cm}$ for men; systolic blood pressure $>130 \mathrm{mmHg}$ and/or diastolic blood pressure $>85 \mathrm{mmHg}$; a triglyceride fasting $>150 \mathrm{mg} / \mathrm{dL}$; a cholesterol $\mathrm{HDL}<40 \mathrm{mg} / \mathrm{dL}$ in men and $<50 \mathrm{mg} / \mathrm{dL}$ in women and fasting glucose greater than or equal to $110 \mathrm{mg} / \mathrm{dL}$ [6].

- Glycemic abnormalities: Hyperglycemia if fasting glucose is $\geq 110 \mathrm{mg} / \mathrm{dL}$ and diabetes if the fasting glucose is $\geq 126 \mathrm{mg} / \mathrm{dL}$.

- Dyslipidemia: Total Hypercholesterolemia (values $\geq 200 \mathrm{mg} / \mathrm{dL}$ ), LDL Hypercholesterolemia ( $\geq 130 \mathrm{mg} / \mathrm{dL}$ ), HDL hypocholesterolemia ( $<35 \mathrm{mg} / \mathrm{dL}$ in men and $<45 \mathrm{mg} / \mathrm{dL}$ in women), hypertriglyceridemia $(\geq 200$ $\mathrm{mg} / \mathrm{dL}$ ).

- The lipodystrophy was defined by the presence of at least one characteristic sign reported by the patient and confirmed by the doctor or objectified by the doctor and approved by the patient. Lipoatrophy were distinguished (thinned skin atrophy of the face, protrusion of the muscles and/or veins, flattening of the buttocks), lipohypertrophy (abdominal hypertrophy, breast, buffalo hump) or a mixed form.

\subsection{Statistics}

Computer tools Epi Data and SAS version 9.2 (SAS Institute, Cary, North Carolina, USA) were used for codification, data entry and statistical analysis. Quantitative variables were described by calculating their mean and standard deviation. Their comparisons were made by Student's test. By cons for qualitative variables, we determined the prevalence. The Khi2 or fischer tests were used for their comparisons. The binomial regression univariate and multivariate analysis was used to identify factors significantly associated with the metabolic syndrome. Tests were performed with a 5\% significance level and a 95\% confidence interval.

\subsection{Ethical Considerations}

Participation in the study was voluntary with informed consent. Data collection sheets and blood samples were identified by an anonymous number. The lipid blood test is not part of routine examinations free and was paid by the research team. Patients in whom metabolic anomalies were observed receive a treatment or adequately monitored.

\section{Results}

\subsection{General Characteristics of the Study Population}

The 420 enrolled patients included $68 \%$ women: $74 \%$ in the group of subjects treated versus $61 \%$ in those untreated $(p=0.005)$. Their average age was $39 \pm 10$ years (extremes: 19 and 81 years). Patients treated were older than untreated: average age $41 \pm$ equal 10 years versus $36 \pm 10$ years $(p=0.001)$. The majority of the subjects treated has been received for the first time in the center at clinical stage 3 or 4 WHO: $65 \%$ versus $35 \%$ ( 
0.001 ) with a CD4 count $\leq 200$ cells $/ \mathrm{mm}^{3}: 81 \%$ versus $16 \%$. The history and other clinical characteristics were comparable in both groups (Table 1$)$. In treated patients $(n=210)$, the duration of treatment was greater than 48 months in 52\% of cases between 24 and 48 months in $25 \%$ of cases and less than 24 months in $23 \%$ of cases. ART was a triple therapy consisting of two nucleoside reverse transcriptase inhibitors (NRTIs) and a third agent which is a non-nucleoside reverse transcriptase inhibitor (NNRTI) or a protease inhibitor. The most commonly used NRTI combination are stavudine + lamivudine (63\%) and zidovudine + lamivudine (21\%). NNRTIs were used by $86 \%$ of patients and protease inhibitors by $14 \%$ of patients.

\subsection{Prevalence of the Metabolic Syndrome and Other Metabolic Abnormalities}

Of the 420 PLWHA, 66 (16\%) had metabolic syndrome including 38 treated and 28 untreated subjects. The prevalence of metabolic syndrome was $18 \%$ in the group of subjects treated versus $13 \%$ in the group of untreated: OR $=1.36$ [0.87 to 2.13]; $\mathrm{p}=0.18$ (Figure 1). The prevalence of other metabolic abnormalities as the subject is treated or untreated with antiretroviral drugs is presented in Table 2.

\subsection{Factors Associated with Metabolic Syndrome}

In univariate analysis, the clinical factors associated with metabolic syndrome were age, hypertension, diabetes (personal or family) and BMI (Table 3). Exposure to NNRTIs increased the risk of developing metabolic syndrome by $25 \%(\mathrm{OR}=1.25$ [0.80 to 1.96]; $\mathrm{p}=0.31)$. It is the same for exposure to protease inhibitors $(\mathrm{OR}=1.26$ [0.62 to 2.56]; $\mathrm{p}=0.51$ ). A more detailed analysis was then carried out with different antiretroviral drugs (Table 4). A statistically significant relationship was observed for exposure to stavudine or indinavir boosted by ritonavir which increased by $59 \%$ and $123 \%$ respectively, the risk of developing the metabolic syndrome. In multivariate analysis, hypertension $\left(\mathrm{OR}_{\mathrm{ajusted}}=1.38\right.$ [1.38 to 3.54]; $\left.\mathrm{p}=0.0009\right)$ and exposure to stavudine $\left(\mathrm{OR}_{\mathrm{ajusted}}=1.55\right.$ [1.06 to 2.27]; $\mathrm{p}=0.02$ ) had proved to be predictors of metabolic syndrome.

Table 1. General characteristics of the study population.

\begin{tabular}{|c|c|c|c|c|}
\hline & $\begin{array}{c}\text { Total enrollment } \\
n=420\end{array}$ & $\begin{array}{l}\text { Patients treated } \\
\quad \mathbf{n}=\mathbf{2 1 0}\end{array}$ & $\begin{array}{l}\text { Patients untreated } \\
n=210\end{array}$ & p value ${ }^{\mu, \dagger}$ \\
\hline Mean age \pm SD (years) & $39 \pm 10$ & $41 \pm 10$ & $36 \pm 10$ & 0.001 \\
\hline \multicolumn{5}{|l|}{ Gender n (\%) } \\
\hline Male & $135(32)$ & $54(26)$ & $81(39)$ & \\
\hline Female & $285(68)$ & $156(74)$ & $129(61)$ & 0.005 \\
\hline \multicolumn{5}{|l|}{ Antecedent to admission $\mathrm{n}(\%)$} \\
\hline Alcoholism & $32(8)$ & $11(5)$ & $21(10)$ & 0.06 \\
\hline Smoking & $19(5)$ & 7 (3) & $12(6)$ & 0.24 \\
\hline Hypertension & $35(8)$ & $19(9)$ & $16(8)$ & 0.59 \\
\hline Diabetes & $13(3)$ & $8(4)$ & $5(2)$ & 0.39 \\
\hline Family hypertension & $172(41)$ & $78(37)$ & $94(45)$ & 0.11 \\
\hline Family diabetes & $71(17)$ & 37 (18) & $34(16)$ & 0.69 \\
\hline HIV-1 n (\%) & 418 (99) & $210(100)$ & 208 (99) & 0.5 \\
\hline \multicolumn{5}{|l|}{ BMI $\left(\mathbf{k g} / \mathbf{m}^{2}\right)$ n (\%) } \\
\hline$<25$ & $280(67)$ & $143(68)$ & $137(65)$ & \\
\hline $25-30$ & $96(23)$ & $48(23)$ & $48(23)$ & \\
\hline$\geq 30$ & $44(10)$ & $19(9)$ & $25(12)$ & 0.62 \\
\hline \multicolumn{5}{|l|}{ WHO stage at admission (\%) } \\
\hline Stage 1 and 2 & $209(50)$ & $73(35)$ & $136(65)$ & \\
\hline Stage 3 and 4 & $211(50)$ & $137(65)$ & $74(35)$ & 0.001 \\
\hline \multicolumn{5}{|l|}{ Initial CD4 (cells/mm³) n (\%) } \\
\hline$\leq 200$ & $203(48)$ & $170(81)$ & $33(16)$ & \\
\hline $200-350$ & $84(20)$ & $34(16)$ & $50(24)$ & \\
\hline$\geq 350$ & $133(32)$ & $6(3)$ & $127(60)$ & $<0.001$ \\
\hline Last CD4 $>200$ cells $/ \mathrm{mm}^{3} \mathrm{n}(\%)$ & $329(78)$ & $158(75)$ & $171(82)$ & 0.30 \\
\hline
\end{tabular}

$\dagger$ : chi-square test for comparing proportions; $\mu$ : Student test for comparison of averages. 


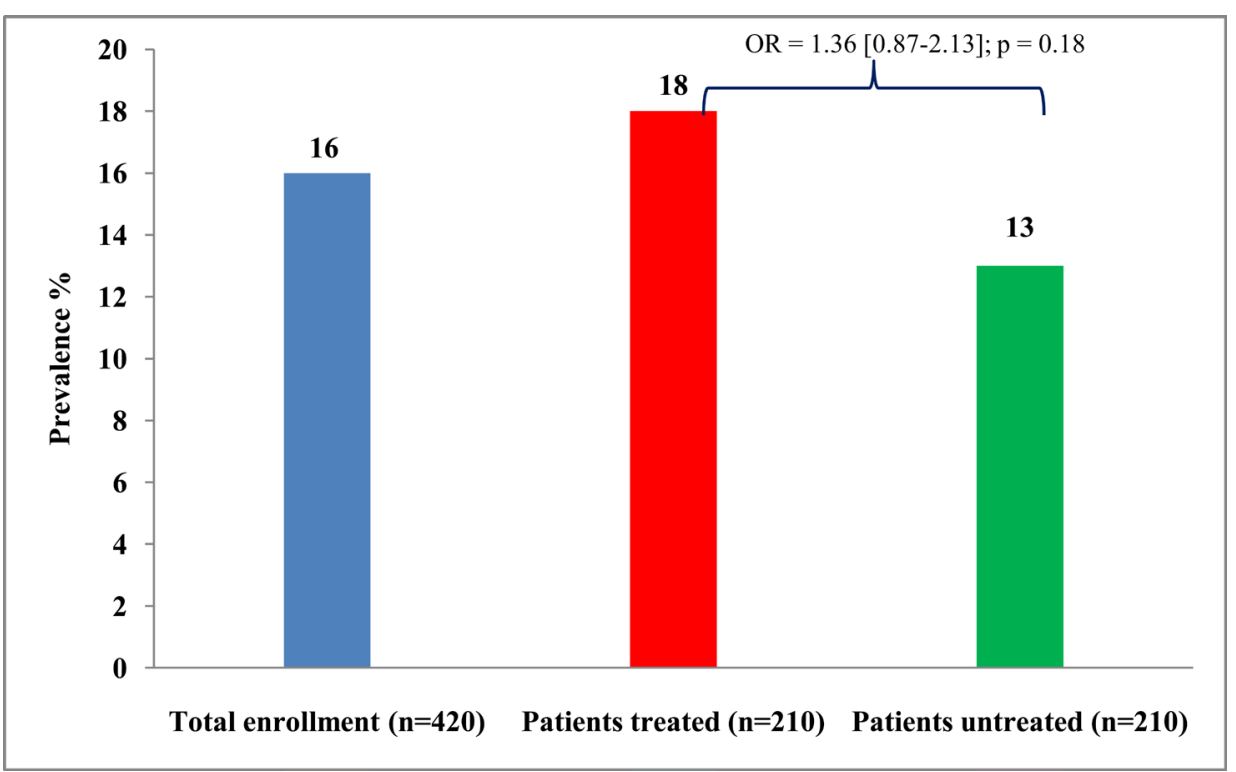

Figure 1. Prevalence of metabolic syndrome among people living with HIV treated or untreated by antiretroviral drugs.

Table 2. Other metabolic abnormalities observed in treated and untreated patients by antiretrovirals.

\begin{tabular}{ccccc}
\hline & $\begin{array}{c}\text { Total enrollment } \\
\mathbf{n = 4 2 0}\end{array}$ & $\begin{array}{c}\text { Patients treated } \\
\mathbf{n = 2 1 0}\end{array}$ & $\begin{array}{c}\text { Patients untreated } \\
\mathbf{n = 2 1 0}\end{array}$ & value $^{\dagger}$ \\
Glycemic abnormalities n (\%) & & & & \\
Hyperglycemia & $46(11)$ & $38(18)$ & $8(4)$ & $<0.0001$ \\
Diabetes & $29(7)$ & $25(12)$ & $4(2)$ & $<0.0001$ \\
Dyslipidemia n(\%) & & & \\
Hyper TC & $121(29)$ & $93(44)$ & $28(13)$ & 0.02 \\
Hyper LDL-C & $156(37)$ & $121(78)$ & $35(22)$ & $<0.0001$ \\
Hypo HDL-C & $281(67)$ & $121(58)$ & $160(76)$ & 0.0001 \\
Hyper TG & $8(2)$ & $4(2)$ & $4(2)$ & 1 \\
Lipodystrophy n (\%) & NA & $62(29)$ & NA & \\
Lipoatrophy & NA & $34(16)$ & NA & NA \\
Lipohypertrophy & NA & $17(8)$ & NA & \\
Mixedlipodystrophy & NA & $11(5)$ & & \\
\hline
\end{tabular}

${ }^{\dagger}$ Comparison of treated versus untreated patients; TC: Total Cholesterol; LDL-C: LDL cholesterol; HDL-C: HDL cholesterol; TG: triglycerides; NA: not applicable.

Table 3. Association between metabolic syndrome and clinical factors in people living with HIV.

\begin{tabular}{|c|c|c|c|c|}
\hline & \multicolumn{2}{|c|}{ Metabolic syndrome n (\%) } & \multirow{2}{*}{ OR [IC $\left.{ }^{\ddagger}(95 \%)\right]$} & \multirow{2}{*}{ Value $\mathbf{p}^{\dagger}$} \\
\hline & Yes & No & & \\
\hline $\operatorname{Age}^{y}$ (year) & - & - & $1.03[1.01-1.04]$ & $<0.0001$ \\
\hline $\begin{array}{l}\text { Gender } \\
\text { Male } \\
\text { Female }\end{array}$ & $\begin{array}{l}20(15) \\
46(16)\end{array}$ & $\begin{array}{l}115(85) \\
239(84)\end{array}$ & $\begin{array}{c}1 \\
1.09[0.67-0.87]\end{array}$ & 0.72 \\
\hline $\begin{array}{c}\text { Hypertension } \\
\text { No } \\
\text { Yes }\end{array}$ & $\begin{array}{l}48(12) \\
18(51)\end{array}$ & $\begin{array}{c}337(88) \\
17(49)\end{array}$ & $\begin{array}{c}1 \\
4.12[2.72-6.26]\end{array}$ & $<0.001$ \\
\hline $\begin{array}{l}\text { Diabetes } \\
\text { No } \\
\text { Yes }\end{array}$ & $\begin{array}{c}59(15) \\
7(54)\end{array}$ & $\begin{array}{c}348(85) \\
6(46)\end{array}$ & $\begin{array}{c}1 \\
3.71[2.13-6.47]\end{array}$ & $<0.001$ \\
\hline $\begin{array}{c}\text { Family Hypertensi } \\
\text { No } \\
\text { Yes }\end{array}$ & $\begin{array}{l}40(16) \\
26(15)\end{array}$ & $\begin{array}{l}208(84) \\
146(85)\end{array}$ & $\begin{array}{c}1 \\
0.94[0.59-1.48]\end{array}$ & 0.77 \\
\hline
\end{tabular}




\section{Continued}

\begin{tabular}{|c|c|c|c|c|}
\hline Family diabetes & & & & \\
\hline No & $47(13)$ & 302 (87) & 1 & \\
\hline Yes & $19(27)$ & 302 (87) & $1.98[1.24-3.18]$ & 0.004 \\
\hline \multicolumn{5}{|l|}{ Alcoholism } \\
\hline No & 57 (15) & 331 (85) & 1 & \\
\hline Yes & $9(28)$ & $23(72)$ & $1.9[1.04-3.50]$ & 0.03 \\
\hline \multicolumn{5}{|l|}{ Smoking } \\
\hline No & $63(16)$ & 338 (84) & 1 & \\
\hline Yes & $3(16)$ & $16(84)$ & $1[0.35-2.91]$ & 0.99 \\
\hline \multicolumn{5}{|l|}{ WHO Stage } \\
\hline Stage 1 and Stage 2 & $29(19)$ & $180(81)$ & 1 & \\
\hline Stage 3 and Stage 4 & 37 (18) & $174(82)$ & $1.26[0.81-1.98]$ & 0.30 \\
\hline \multicolumn{5}{|l|}{ BMI $\left(\mathrm{kg} / \mathrm{m}^{2}\right)$} \\
\hline$<25$ & $24(9)$ & $256(91)$ & 1 & \\
\hline $25-30$ & $23(24)$ & $73(76)$ & $2.80[1.66-4.71]$ & \\
\hline$\geq 30$ & $19(43)$ & $25(57)$ & $5.04[0.22-0.87]$ & $<0.001$ \\
\hline \multicolumn{5}{|l|}{ InitialCD4 (cells/mm³) } \\
\hline$\leq 200$ & $32(16)$ & $171(84)$ & 1 & \\
\hline $200-350$ & $9(11)$ & 75(89) & $0.68[0.34-1.36]$ & \\
\hline$\geq 350$ & $25(19)$ & $108(81)$ & $1.19[0.74-1.92]$ & 0.3 \\
\hline Last CD4 ${ }^{¥}\left(\right.$ cells $\left./ \mathrm{mm}^{3}\right)$ & - & - & $1[1-1.03]$ & 0.08 \\
\hline
\end{tabular}

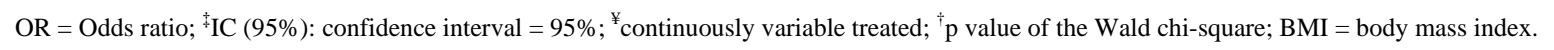

Table 4. Association between metabolic syndrome and exposure to antiretroviral drugs in people living with HIV.

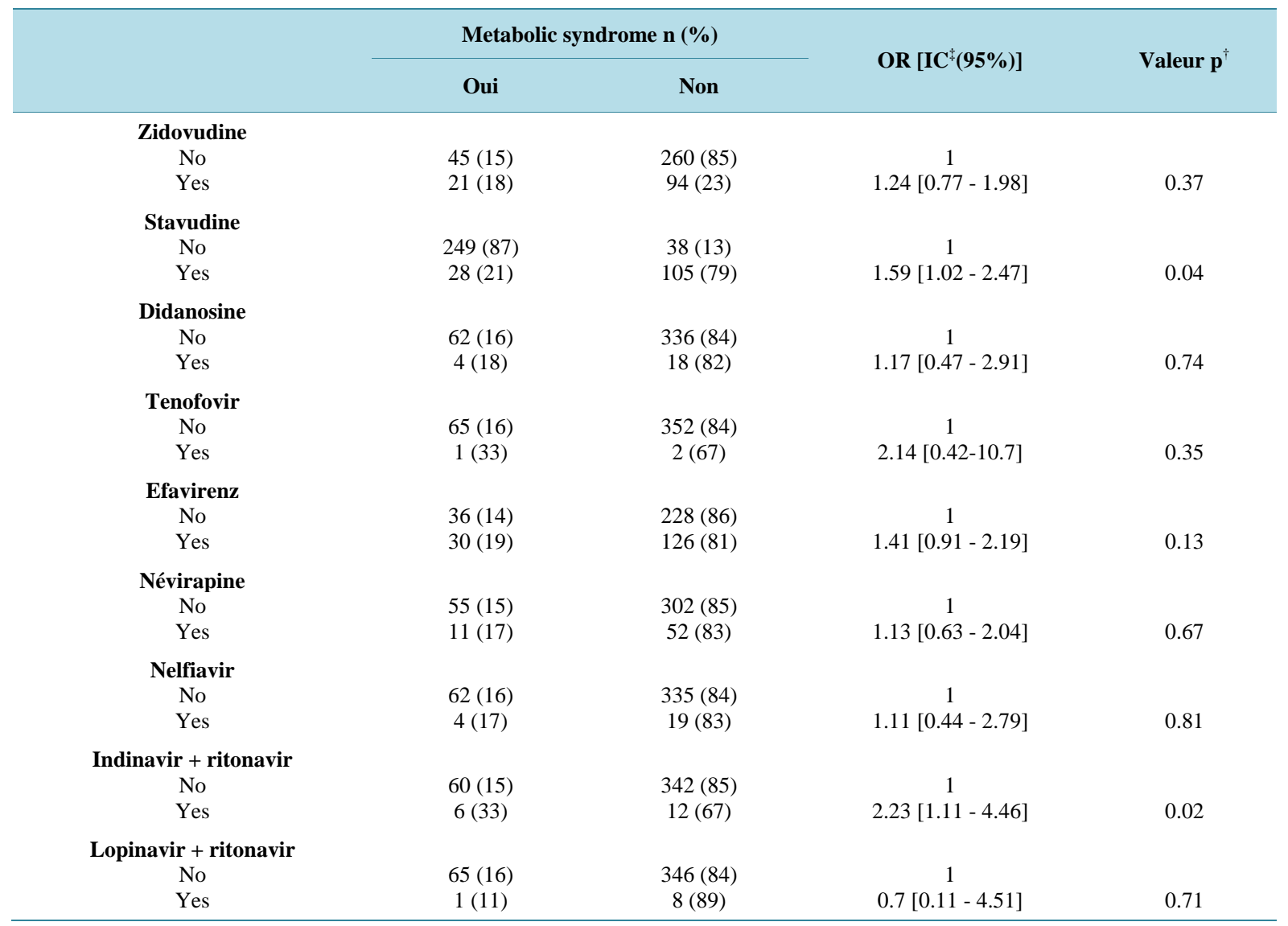

OR = Odds ratio; ${ }^{\ddagger} \mathrm{IC}(95 \%)$ : confidence interval $=95 \%$; ${ }^{\sharp}$ continuously variable treated; ${ }^{\dagger} \mathrm{p}$ value of the Wald chi-square for comparison of patients who have undergone at least once exposure to each molecule, versus those who have never suffered, including untreated patients. 


\section{Discussion}

The prevalence of metabolic syndrome in our study population, according to the NCEP-ATP III was 16\%: 18\% in the group treated versus $13 \%$ in untreated with no significant difference. In Africa, the frequency of metabolic syndrome varies from $10 \%$ to $21 \%$ in patients receiving ART [5] [7] [8]. This frequency is strongly related to the diagnosis criteria which are those of IDF (International Diabetes Federation) or those of NCEP-ATP III. The reported studies also showed just as we observed that there is no significant difference between the treated and untreated subjects. Therefore, the authors question the real impact of ARV treatment on the onset of metabolic syndrome. Actually, the duration of exposure to ARV was highly variable in the cohort of patients studied. Nearly half of the patients had less than 48 months of exposure (between 24 and 48 months in $25 \%$ of cases and less than 24 months in 23\% of cases); which could explain the difference between our two patient groups was not significant. Logically, the incidence of metabolic disorders increases with the duration of exposure to ARVs [5]. If we compared subjects treated for more than 48 months to untreated subjects, we could probably observe a significant difference. In our study, although there was no significant difference between the 2 groups, ART increased to $36 \%$ the risk of developing metabolic syndrome. On the other metabolic abnormalities, the impact of ART is significantly remarkable. Indeed, hyperglycemia was observed in $18 \%$ of patients (including $12 \%$ diabetes) versus $4 \%$ in untreated subjects (including $2 \%$ diabetes), $\mathrm{p}<0.0001$. Guira $\mathrm{O}$. in Burkina Faso found that $29.6 \%$ of subjects had hyperglycemia [7]. Likewise the lipid profile of subjects treated is different from that of untreated: $44 \%$ had hypercholesterolemia versus $13 \%, p=0.02$. In fact, the high frequency of these anomalies is reported by several studies but in widely varying proportions [5]-[10]. Lipodystrophy was observed in nearly one patient treated for three, and more than half of the cases were the atrophic form. Others have made the same observation emphasizing the determining role of stavudine which was widely used in most national programs in developing countries [5] [7] [11]. The impact of ART on the occurrence of metabolic syndrome is due to the mechanism of action of ARVs Drugs which determine dysfunction of lipid and glucose metabolism of patients [12]-[15]. The high prevalence of metabolic syndrome in patients exposes them more to cardiovascular disease [16] [17] and diabetes [18] [19]. The risk to develop diabetes in our patients treated was 6 times that of untreated. Some studies have shown that IP was the most complained therapeutic class in the occurrence of metabolic syndrome [3] [6] [9]. In ours, we achieved the same results. Indinavir boosted with ritonavir was associated with a high risk to developed metabolic syndrome, with a measure of association of 2.23. Besides the IP, other studies have also incriminated some NRTIs, particularly the stavudine, in the occurrence of metabolic syndrome [5] [6]. This association was also documented in our cohort in which exposure to stavudine increased to $59 \%$ the risk to develop metabolic syndrome.

Classically, age is quoted in the general population, as a cardiovascular risk factor. It is the same in PLWHA. Indeed, PLWHA, aged over 50, have a history of the disease and treatment history longer than the younger subjects and thus would develop more of metabolic abnormalities. Various studies confirm these facts [5]-[8] [20]. In our study, a difference of one year of age significantly increased by $0.3 \%$ the risk to develop metabolic syndrome.

BMI was statistically associated with the occurrence of the metabolic syndrome in our study population. Patients overweight and obese had respectively 3 and 5 times the risk of those with a weight below normal. Patients who are overweight are more wear priori to present abdominal obesity and dyslipidemia than others. However, abdominal obesity and dyslipidemia are key parameters for the diagnosis of metabolic syndrome. The relationship between BMI and the metabolic syndrome can explain this fact. It was also observed in most of the previous studies. In France, the SHIVA cohort [21] in 2008, the average BMI of patients with metabolic syndrome was $26 \pm 3.3$ (p = 0.002) and in the SYMET cohort (metabolic syndrome) [10], after a four years of ART, patients with an increase in BMI during follow-up, quadrupled their risk of developing metabolic syndrome $(\mathrm{p}=$ 0.002). It is the same in a Spanish cohort in 2003, with an average BMI of $25.8 \pm 3.7$ (OR = 1.27, p = 0.0001) [6]. Immune restoration allows, in subjects with HIV infection, weight gain need to be monitored to prevent or detect early consequent metabolic abnormalities, as has been shown in the study by DUBE and al [22] in naive patients, with a correlation between weight gain in the first six months after initiation of therapy and visceral perished fat content measured by DEXA scan.

Patients who consume alcohol increase $90 \%$ their risk of developing metabolic syndrome. The metabolic syndrome is associated with an inflammation of the adipose tissue with macrophage infiltration in the original hyperproduction of pro-inflammatory cytokines, an increase in the free fatty acid stream and a decrease of adiponectin, resulting hepatic lipotoxicity, or steatohepatitis [23]. However, it has been shown greater severity of 
liver damage in alcoholic patients, regardless of any other abuse of the liver, such viral hepatitis C [24]. Alcohol consumption among PLWHA could therefore accelerate by its liver toxicity, metabolic dysfunction, thereby increasing the risk of developing metabolic syndrome. High blood pressure, diabetes and a family history of diabetes, increased risk of developing metabolic syndrome in patients treated. The association between metabolic syndrome and these diseases (hypertension and diabetes) could result from the fact that they are already included risk factors in the diagnostic criteria of metabolic syndrome. In most studies, patient histories were not documented. Some studies even take as exclusion criteria, the fact of presenting one or the other of these antecedents. In the SHIVA study (Study of HIV and Atherosclerosis) on a cohort of HIV treatment in France [21], patients with a known history of hypertension, diabetes and family history of cardiovascular disease, were excluded from the sample. By integrating subjects with a family history of cardiovascular disease, the prevalence of metabolic syndrome increased from $7.1 \%$ to $10.3 \%$. It would be interesting to conduct longitudinal studies to document the installation of the metabolic syndrome in PLWHA including patients treated with ARVs who are hypertensive or diabetic. After multivariate analysis, factors associated with statistics significantly to the occurrence of the metabolic syndrome were hypertension and exposure to stavudine. These variables collectively increased from $38 \%$ to $55 \%$ the risk to develop metabolic syndrome. So, with these variables, we can predict for the individual risk of developing metabolic syndrome.

\section{Conclusion}

The impact of antiretroviral therapy on the metabolic profile of PLWHA is real. Classical cardiovascular risk factors (including age, overweight, hypertension, and diabetes) and the use of certain ARVs drugs as indinavir boosted by ritonavir and stavudine predispose to the occurrence of the metabolic syndrome in these types of patients. In developing countries, in support of national programs for PLWHA the use of ARVs at high risk of metabolic disorders must definitively be ended. They also must imperatively implement prevention strategies and management of metabolic abnormalities in treated PLWHA. In doing so, we can expect long-term minimizing the risk of cardiovascular events in PLWHA.

\section{Acknowledgements}

We are grateful to the entire team Ambulatory care center for people living with HIV at CNHU-Hubert K. Maga and Dr. Idrissou Abdoulaye, head of the Laboratory of Biochemistry CNHU-Hubert K. Maga for their valuable contributions.

\section{References}

[1] Signorini, D.J., Monteiro, M.C., Andrade Mde, F., Signorini, D.H. and Eyer-Silva Wde, A. (2012) What Should We Know about Metabolic Syndrome and Lipodystrophy in AIDS? Revista da Associação Médica Brasileira, 58, 70-75. http://dx.doi.org/10.1016/S0104-4230(12)70157-4

[2] Niakara, A., Drabo, Y.J., Kambire, Y., Nebie, L.V.A., Kabore, N.J.P. and Simon, F. (2002) Atteintes cardio-vasculaires et infection par le VIH : étude de 79 cas au CHN de Ouagadougou (Burkina Faso). Bulletin de la Société de Pathologie Exotique, 95, 23-26.

[3] Friis-Moller, N., Sabin, C.A. and Weber, R., The Data Collection on Adverse Events of Anti-HIV Drugs (DAD) Study Group (2003) Combination Antiretroviral Therapy and the Risk of Myocardial Infarction. The New England Journal of Medicine, 349, 1993-2003. http://dx.doi.org/10.1056/NEJMoa030218

[4] May, T., Lewden, C., Bonnet, F., Heripret, L., Bevilacqua, S., Jougla, E., et al. (2004) Causes et caractéristiques des décès des patients infectés par le VIH-1 en succès immuno-virologique, sous traitement antirétroviral. La Presse Médicale, 33, 1487-1492. http://dx.doi.org/10.1016/S0755-4982(04)98968-3

[5] Zannou, D.M., Denoeud, L., Lacombe, K., Amoussou-Guenou, D., Bashi, J., Akakpo, J., et al. (2009) Incidence of Lipodystrophy and Metabolic Disorders in Patients Starting Non-Nucleoside Reverse Transcriptase Inhibitors in Benin. Antiviral Therapy, 14, 371-380.

[6] Samaras, K., Wand, H., Law, M., Emery, S., Cooper, D. and Carr, A. (2007) Prevalence of Metabolic Syndrome in HIV-Infected Patients Receiving Highly Active Antiretroviral Therapy Using International Diabetes Foundation and Adult Treatment Panel III Criteria: Associations with Insulin Resistance, Disturbed Body Fat Compartmentalization, Elevated C-Reactive Protein, and Hypoadiponectinemia. Diabetes Care, 30, 113-119. http://dx.doi.org/10.2337/dc06-1075

[7] Guira, O., Tiéno, H., Diendéré, A.E., Sagna, Y., Diallo, I., Yaméogo, B., et al. (2015) Features of Metabolic Syndrome 
and Its Associated Factors during Highly Active Antiretroviral Therapy in Ouagadougou (Burkina Faso). Journal of the International Association of Providers of AIDS Care (JIAPAC), 1-5. http://dx.doi.org/10.1177/2325957415601503

[8] Ayodele, O.E., Akinboro, A.O., Akinyemi, S.O., Adepeju, A.A., Akinremi, O.A., Alao, C.A. and Popoola, A.A. (2012) Prevalence and Clinical Correlates of Metabolic Syndrome in Nigerians Living with Human Immunodeficiency Virus/ Acquired Immunodeficiency Syndrome. Metabolic Syndrome and Related Disorders, 10, 373-379. http://dx.doi.org/10.1089/met.2012.0050

[9] Martinez, E., Domingo, P., Galindo, M.J., Milinkovic, A., Arroyo, J.A., Baldovi, F., et al. (2004) Risk of Metabolic Abnormalities in Patients Infected with HIV Receiving Antiretroviral Therapy That Contains Lopinavir-Ritonavir. Clinical Infectious Diseases, 38, 1017-1023. http://dx.doi.org/10.1086/382531

[10] Biron, C., Bobin-Dubigeon, C., Leport, C., Piroth, L., Perré, P., Bard, J.M. and Raffi, F. (2008) Syndrome métabolique chez les patients VIH sous HAART depuis 1 an à 4 ans : Etude SYMET. Médecine et Maladies Infectieuses, 38, S172. http://dx.doi.org/10.1016/s0399-077x(08)73197-4

[11] Kalyanasundaram, A.P., Jacob, S.M., Hemalatha, R. and Sivakumar, M.R. (2012) Prevalence of Lipodystrophy and Dyslipidemia among Patients with HIV Infection on Generic ART in Rural South India. Journal of the International Association of Physicians in AIDS Care, 11, 329-334. http://dx.doi.org/10.1177/1545109711401750

[12] Murata, H., Hruz, P.W. and Muechler, M. (2002) The Mechanisms of Insulin Resistance Caused by HIV Protease Inhibitor Therapy. The Journal of Biological Chemistry, 275, 20251-20254. http://dx.doi.org/10.1074/jbc.C000228200

[13] Mooser, V. and Caar, A. (2001) Antiretroviral Therapy-Associated Hyperlipidaemia in HIV Disease. Current Opinion in Lipidology, 12, 313-319. http://dx.doi.org/10.1097/00041433-200106000-00011

[14] Riddle, T., Kuhel, D., Woollett, L., Fichtenbaum, C. and Hui, D.Y. (2001) HIV Protease Inhibitor Induces Fatty Acid and Sterol Biosynthesis in Liver and Adipose Tissues Due to the Accumulation of Activated Sterol Regulatory Element Binding Proteins in the Nucleus. The Journal of Biological Chemistry, 276, 37514-37519. http://dx.doi.org/10.1074/jbc.m104557200

[15] Blanco, F., San Román, J., Vispo, E., Lopez, M., Salto, A., Abad, V. and Soriano, V. (2010) Management of Metabolic Complications and Cardiovascular Risk in HIV-Infected Patients. AIDS Reviews, 12, 231-241.

[16] Mondy, K.E., de las Fuentes, L. and Waggoner, A. (2008) Insulin Resistance Predicts Endothelial Dysfunction and Cardiovascular Risk in HIV-Infected Persons on Long-Term Highly Active Antiretroviral Therapy. AIDS, 22, 849-856. http://dx.doi.org/10.1097/QAD.0b013e3282f70694

[17] Zannou, D.M., Tchabi, Y., Ahomadégbé, C., Akakpo, J., Azon-Kouanou, A., Adé, G., et al. (2013) Cardiovascular Risk among People Living with HIV at the Academic Hospital of Cotonou, Bénin. Médecined'Afrique Noire, 60, 419-426.

[18] Yoon Cecilia, J. (2005) Le diabète chez les personnes atteintes du VIH. Diabetesvoice, 50, 13-15.

[19] Bakari, A.G., Sani-Bello, F., Shehu, M.S., Mai, A., Ibrahim, S.A. and Ibrahim, I.L. (2007) Antiretroviral Therapy Induced Diabetes in a Nigerian. African Health Sciences, 7, 133-135.

[20] Leitner, J.M., Pernerstorfer-Schoen, H., Weiss, A., Schindler, K., Rieger, A. and Jilma, B. (2006) Age and Sex Modulate Metabolic and Cardiovascular Risk Markers of Patients after 1 Year of Highly Active Antiretroviral Therapy (HAART). Atherosclerosis, 187, 177-185. http://dx.doi.org/10.1016/j.atherosclerosis.2005.09.001

[21] de Saint Martin, L., Pasquier, E., Roudaut, N., Vandhuick, O., Vallet, S., Bellein, V. and Bressollette, L. (2008) Metabolic Syndrome : A Major Risk Factor for Atherosclerosis in HIV-Infected Patients (SHIVA Study). La Presse Médicale, 37, 579-584. http://dx.doi.org/10.1016/j.lpm.2007.09.022

[22] Dube, M.P., Parker, R.A. and Tebas, P. (2005) Glucose Metabolism, Lipid, and Body Fat Changes in AntiretroviralNaive Subjects randomized to Nelfinavir or Efavirenz Plus Dual Nucleosides. AIDS, 19, 1807-1818. http://dx.doi.org/10.1097/01.aids.0000183629.20041.bb

[23] Serfaty, L., Mathurin, P., Cadranel, J.F. and Tran, A. (2007) Alcool, syndrome métabolique et obésité: Impact sur la réponse au traitement. Gastroentérologie Clinique et Biologique, 31, 40-43. http://dx.doi.org/10.1016/S0399-8320(07)92562-2

[24] Poynard, T., Bedossa, P. and Opolon, P., for the OBSVIR, METAVIR, CLINIVIR, and DOSVIR Groups (1997) Natural History of Liver Fibrosis Progression in Patients with Chronic Hepatitis C. Lancet, 349, 825-832. http://dx.doi.org/10.1016/S0140-6736(96)07642-8 